\title{
Nominal Scale
}

National Cancer Institute

\section{Source}

National Cancer Institute. Nominal Scale. NCI Thesaurus. Code C47798.

A scale that uses only categ ories, with no inherent order. (www.referencewordsmith.com) 